\title{
Role of dopants in Bi-Sr-Ca-Cu-O system
}

\author{
B V REDDI*, I G VASILYEVA**, A I ROMANENKO** and \\ V V MALACHOV ${ }^{\dagger}$ \\ * National Physical Laboratory, Dr K.S. Krishnan Road, New Delhi 110012, India \\ **Institute of Inorganic Chemistry, Novosibirsk-630090, USSR \\ ${ }^{\dagger}$ Institute of Catalysis, Novosibirsk-630090, USSR
}

\begin{abstract}
The role of $\mathrm{Al}$ and $\mathrm{Ag}$ dopants in the nominal composition, 4336 of $\mathrm{Bi}-\mathrm{Sr}-\mathrm{Ca}-\mathrm{Cu}$ oxide has been studied, using a new chemical phase analysis method known as differential dissolution besides XRD and resistivity and magnetic susceptibility measurements. Our investigation reveals that (a) it is relatively easy to realize high- $T_{c}$ phase (2223) in both Al-and Ag-doped samples with the same nominal composition and heat treatment history (b) both samples consist of superconducting phases with more or less the same basic composition and equal amounts, (c) 2112 phase may be a superconductor and (d) superconducting properties with $\mathrm{Al}$ and $\mathrm{Ag}$ dopants are different.
\end{abstract}

Keywords. High-temperature superconductivity; $\mathrm{Bi}-\mathrm{Sr}-\mathrm{Ca}-\mathrm{Cu}-\mathrm{O}$; dopants, differential dissolution phase analysis, polytypoid structures; long-range ordering.

\section{Introduction}

It is well known that there are two high temperature superconducting phases in the family of Bi-Sr-Ca-Cu-O (Maeda et al 1988). They are three-layered structures with a chemical composition, $\mathrm{Bi}_{2} \mathrm{Sr}_{2} \mathrm{Ca}_{2} \mathrm{Cu}_{3} \mathrm{O}_{x}$ and a superconducting transition temperature, $T_{c}$ of $110-115 \mathrm{~K}$ (high- $T_{c}$ phase) as well as a double perovskite-layered phase, $\mathrm{Bi}_{2} \mathrm{Sr}_{2} \mathrm{Ca}_{1} \mathrm{Cu}_{2} \mathrm{O}_{x}$ with $T_{c}$ of $75-85 \mathrm{~K}$ (low- $T_{c}$ phase). The latter is formed relatively easily. Recently it was shown that the high- $T_{c}$ phase precipitates at the interface between the eutectic products - low- $T_{c}$ phase and $\mathrm{Ca}_{2} \mathrm{CuO}_{3}$ phase - and is controlled by calcium and copper diffusion (Shi et al 1989). Therefore many attempts were made to realize high- $T_{c}$ single phase with a careful sintering schedule of proper composition in the narrow temperature range and/or with dopants (Jin et al 1988; Green et al 1989; Kanai et al 1989; Reddi et al 1989a,b). But there is little information on such dopants whether they merely act as catalysts in the nucleation and growth process and/or whether they participate in the crystal lattice of high- $T_{c}$ phase. Only a part of the information could be obtained using diffraction techniques.

In the present study, we have followed a new technique, namely differential dissolution (DD) phase analysis, based on the theoretical background laid by one of the present authors (Malachov 1986, 1989). This method, unlike other diffraction methods, identifies the phases not by their crystal structure but by their composition. It also gives information about the phases present and the degree of dispersion of solute in the material. The advantages of this method have been described elsewhere (Vasilyeva et al 1990). The electrical resistivity and susceptibility were measured along with X-ray analysis to monitor the relationship between superconducting transition temperature and the phases present in the sample. In this paper, the role of dopants, $\mathrm{Ag}$ and $\mathrm{Al}$ on the nominal composition of $\mathrm{Bi}_{4} \mathrm{Sr}_{3} \mathrm{Ca}_{3} \mathrm{Cu}_{6} \mathrm{O}_{x}$ under identical conditions of synthesis is reported. 


\section{Experimental}

Specimens with nominal compositions of $\mathrm{Bi}_{4} \mathrm{Sr}_{3} \mathrm{Ca}_{3} \mathrm{Cu}_{6} \mathrm{O}_{x}$ (hereafter called $\mathrm{Bi}$ ), $\mathrm{Bi}_{4} \mathrm{Sr}_{3} \mathrm{Ca}_{3} \mathrm{Cu}_{6} \mathrm{Al}_{0.2} \mathrm{O}_{x}(\mathrm{Bi}-\mathrm{Al})$ and $\mathrm{Bi}_{4} \mathrm{Sr}_{3} \mathrm{Ca}_{3} \mathrm{Cu}_{6} \mathrm{Ag}_{0.2} \mathrm{O}_{x}(\mathrm{Bi}-\mathrm{Ag})$ were prepared from powders of $\mathrm{Bi}_{2} \mathrm{O}_{3}, \mathrm{CuO}, \mathrm{Al}_{2} \mathrm{O}_{3}, \mathrm{SrCO}_{3}, \mathrm{CaCO}_{3}$ and metallic silver of not less than $99 \%$ purity. They were calcined at $782^{\circ} \mathrm{C}$ for $24 \mathrm{~h}$ followed by grinding and calcination first at the same temperature for $14.5 \mathrm{~h}$ and then at $800^{\circ} \mathrm{C}$ for $145 \mathrm{~h}$ in air. Tablets made from such calcined powders were sintered in air at $848^{\circ} \mathrm{C}$ for $119 \mathrm{~h}$.

Nitric acid was used as a solvant in the DD method. Total dissolution of the specimen was achieved in about $30 \mathrm{~min}$, by which time up to 50 samples of the solution with 1-2 ml volume were taken and all the elements except oxygen determined. $\mathrm{Bi}, \mathrm{Ca}$, $\mathrm{Cu}, \mathrm{Al}$ and $\mathrm{Ag}$ were determined by the method of atomic absorption while $\mathrm{Sr}$ was found by flame emission or by atomic emission analysis of the solutions, using the method of inductive plasma. X-ray phase analysis was done on diffractometer (DRON-3M, USSR make) with filtered $\mathrm{CuK}_{\alpha}$ radiation.

Electrical resistance was measured with In-Ga paste contacts in the standard fourpoint configuration and the temperature dependence of dynamic susceptibility $\chi^{\prime}-i \chi^{\prime \prime}$ measured using the mutual inductance method (Maxwell 1965).

\section{Results and discussion}

A series of parametric dependences for each sample were set out from the data generated in DD method. The total number of parametrical dependences was determined by the number of pair combinations of all the elements except oxygen. The data on parametrical dependences were obtained from the number of moles of each elements in the pair transforming into the solution from the specimen at every moment of time. Thus the number of parametric dependences $(c)$ is determined by the following formula, $c=m / 2(m-2)$ where $m$ is the number of elements (except oxygen) making the sample. There were 6 dependences for undoped (figure 1) and 10 for Ag or Al-doped samples (figure 2) in our work. From these parametric dependences, their interrelationship and kinetic data and qualitative and quantitative information on phase composition were obtained. As shown in figure 2, the specimens, $\mathrm{Bi}-\mathrm{Al}$ and $\mathrm{Bi}-\mathrm{Ag}$ have nonlinear segments, indicating combined dissolution along with neighbouring phases during the corresponding period. The phase uniformly distributed in the sample and dissolved at the end (last phase) has approximate composition, $\mathrm{Bi}: \mathrm{Sr}: \mathrm{Ca}: \mathrm{Cu}=1.5-$ $2.0: 0.5-0.8: 0.7-0.9: 2$. This phase probably acquires an intergrowth structure, which is characteristic for this class of material (Tallon et al 1988). The composition of the main phase was determined sufficiently accurately from the largest segment of parametrical dependence and was found to have $\mathrm{Bi}: \mathrm{Sr}: \mathrm{Ca}: \mathrm{Cu}: \mathrm{Ag}(\mathrm{Al})=1: 1: 1: 1.5: 0.08(0.05)$. It represents the phase $\mathrm{Bi}_{2} \mathrm{Sr}_{2} \mathrm{Ca}_{2} \mathrm{Cu}_{3} \mathrm{O}_{x}(2223)$. Therefore the presence of $\mathrm{Al}(0.05)$ and $\mathrm{Ag}(0.08)$ in 2223 phase was confirmed. A part of $\mathrm{Ag}$ remained as a separate phase, may be in the form of metallic silver. Besides $\mathrm{Ag}$, copper and calcium oxides in highly dispersed state were found in the $\mathrm{Bi}$-Ag sample. These may be the products of secondary processes like substitution, decay and degradation, and that they are not segregated but dispersed uniformly throughout the sample.

The remaining matrices, also called equilibrium matrices (figure 3), give full information of phase compositions of the sample where the data of total mole amount of 
Dopants in $\mathrm{Bi}-\mathrm{Sr}-\mathrm{Ca}-\mathrm{Cu}-\mathrm{O}$
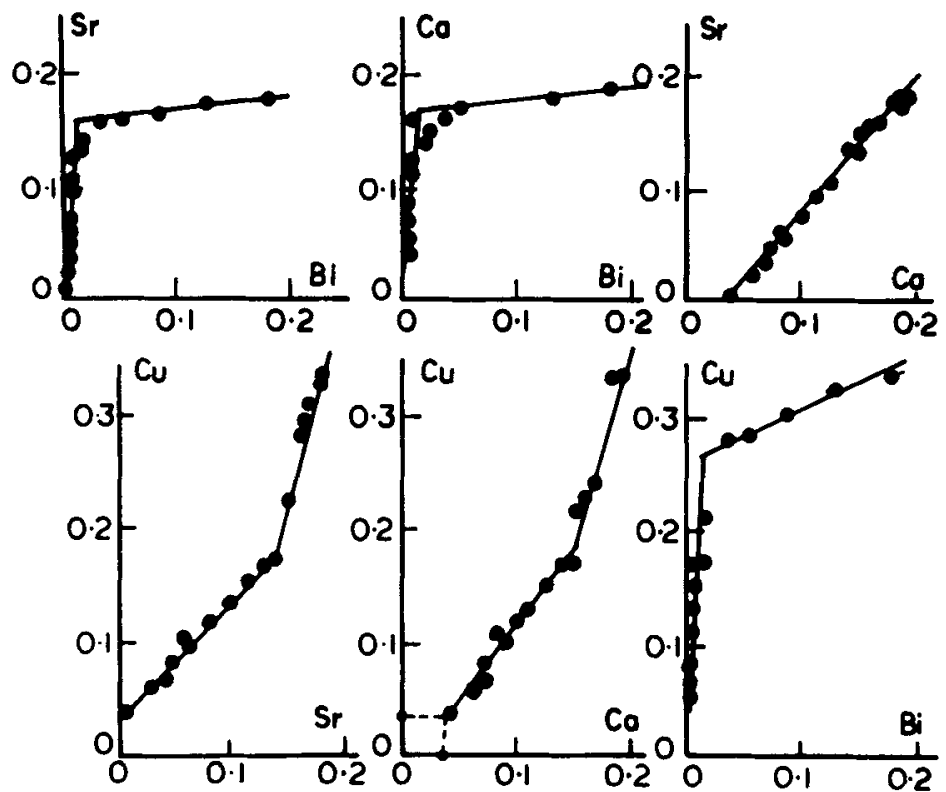

Figure 1. Parametric dependences of the elements in the undoped sample.

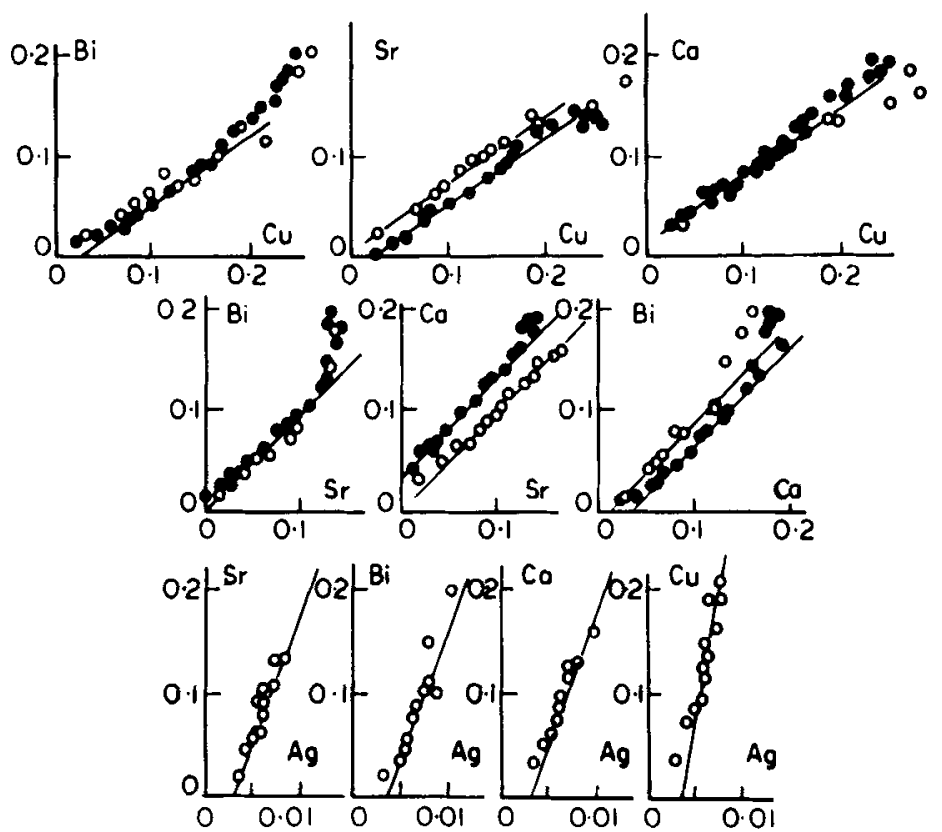

Figure 2. Parametric dependences of the elements in Ag-doped (O) and Al-doped (O) samples. 


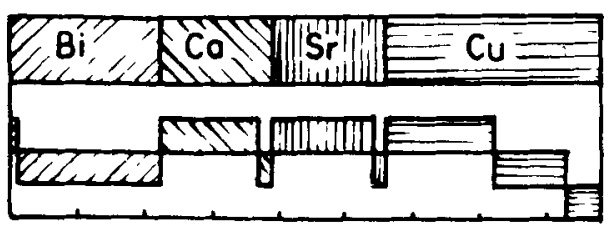

(a)
NOMINAL: $\mathrm{Bi}_{4} \mathrm{Sr}_{3} \mathrm{CO}_{3} \mathrm{Cu}_{6} \mathrm{O}_{x}$

TOTAL: $\mathrm{Bi}_{4} \mathrm{Sr}_{30} \mathrm{Ca}_{30} \mathrm{Cu}_{6} \mathrm{O}_{x}$

Bio. $\mathrm{Sr}_{1.0} \mathrm{C}_{00} \mathrm{Cu}_{3-0} \mathrm{O}_{\mathrm{3}}$ 53\% $\mathrm{Bi}_{1.8} \mathrm{Sr}_{0.1} \mathrm{CO}_{0.1} \mathrm{Cu}_{0.5} \mathrm{O}_{\times} \times 4 \%$

Moss $\% \Sigma 99 \cdot 8 \pm 2 \cdot 0$

NOMINAL: $\mathrm{Bi}_{4} \mathrm{Sr}_{3} \mathrm{CO}_{3} \mathrm{Cu}_{0} \mathrm{Al}_{O_{2}} \mathrm{O}_{\mathrm{X}}$

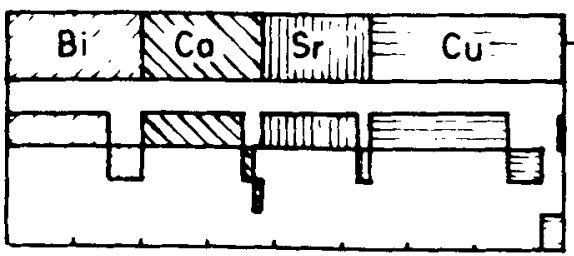

(b)

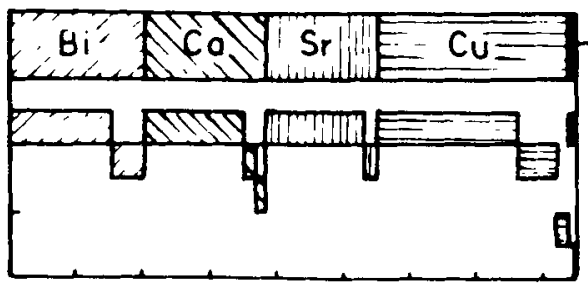

(c)
-AI

\author{
TOTAL: $\mathrm{Bi}_{4} \mathrm{Sr}_{3.08} \mathrm{Co}_{4.0} \mathrm{Cu}_{5.6} \mathrm{Al} 0.05 \mathrm{O}$ \\ $\begin{array}{ll}\mathrm{Bi}_{2} \mathrm{Sr}_{2} \mathrm{CO}_{2} \mathrm{Cu}_{3} \mathrm{Al}_{0.05} \mathrm{O}_{x} & 78 \% \\ \mathrm{Bi}_{2} \mathrm{SrO}_{2} \mathrm{Co}_{0.8} \mathrm{Cu}_{2} \mathrm{O}_{x} & 15 \% \\ \mathrm{CoO} & 1.9 \% \\ \mathrm{CuO} & 3.2 \%\end{array}$
}

$\sum 98 \cdot 1 \pm 2 \cdot 0$

NOMINAL: $\mathrm{Bi}_{4} \mathrm{Sr}_{3} \mathrm{CO}_{3} \mathrm{Cu}_{6} \mathrm{Ag}_{0.2} \mathrm{O}_{x}$ Ag

TOTAL: $\mathrm{Bi}_{4.1} \mathrm{Sr}_{3,1} \mathrm{CO}_{3,1} \mathrm{Cu}_{6.4} \mathrm{Ag}_{0.2} \mathrm{O}_{x}$

$\mathrm{Bi}_{2} \mathrm{Sr}_{2} \mathrm{Co}_{2} \mathrm{Cu}_{3} \mathrm{Ag}_{0.00} \mathrm{O}_{\mathrm{x}} \quad 77 \%$

$\mathrm{Bi}_{2} \mathrm{Sro}_{7} \mathrm{CO}_{0} . \mathrm{Du}_{2} \mathrm{O}_{x} \quad 15 \%$

$\mathrm{CoO}$

$6.6 \%$

Ay

$0.4 \%$

$\Sigma 99.5 \pm 2 \cdot 0$

Figure 3. Balance matrices of (a) undoped, (b) Al-doped and (c) Ag-doped samples.

each component except oxygen, obtained in the DD method is represented by the rows with the columns showing the elements present in the specimen.

As pointed out earlier (Vasilyeva et al 1990) X-ray analysis reveals that the main high- $T_{\mathrm{c}}$ phase is affected only in the presence of $\mathrm{Ag}$ or Al. XRD patterns show the differences between Ag- and Al-doped samples. These differences are associated with classical polytypoid phase, 2223. The alloying with $\mathrm{Ag}$ or $\mathrm{Al}$ leads to subsequent demarcation of polytypoid order. Addition of Al causes local deformation of phase lattice 2223. It is possible that the polytypoid phase of 2112 may also occur with these dopants.

Presence of these dopants in phases and oxides of copper and calcium and their spatial distribution affects the superconducting properties. According to $R(T)$ and the 
Table 1. Superconducting transition temperature and transition width $\left(\Delta T_{c}\right)$ of high- $T_{c}\left(T_{c 1}\right)$ and low $-T_{c}\left(T_{c 2}\right)$ phases obtained from resistivity and susceptibility measurements.

\begin{tabular}{lcccccc}
\hline Specimen & \multicolumn{3}{c}{$R(T)$ measurement } & & \multicolumn{2}{c}{$\chi^{\prime}(T)$ Measurement } \\
\hline & $T_{c 1}$ & $T_{c 2}$ & $\Delta T_{c 1}$ & $\Delta T_{c 2}$ & $T_{c 1}$ & $T_{c 2}$ \\
\cline { 2 - 6 } & & & & & 95 & 78 \\
$\mathrm{Bi}$ & 107 & 70 & 5 & 10 & 104 & 87 \\
$\mathrm{Bi}-\mathrm{Al}$ & 110 & 80 & 3 & 3 & 107.5 & 79 \\
$\mathrm{Bi}-\mathrm{Ag}$ & & & & & & \\
\hline
\end{tabular}

real part $\chi^{\prime}(T)$ measurements, there are two superconductive transitions indicating the presence of two superconducting phases in the $\mathrm{Bi}-\mathrm{Al}$ and $\mathrm{Bi}-\mathrm{Ag}$ specimens with predominant high $T_{c}$-phase $T_{c 1}$. It may be stated that another phase with approximate composition of 2112 , detected by us is superconducting at the lower temperature, $T_{c 2}$. Other parameters like width of the transition of high $\left(\Delta T_{c 1}\right)$ and low $\left(\Delta T_{c 2}\right)$ superconducting phases are shown in table 1 .

It is clear from the table that the superconducting properties of these samples are markedly different from each other depending on the nature of the dopant. Though, in general, high-transition temperatures are observed in both the doped samples, the transition width is greater in the Al-doped sample due to the effect of greater local distortion caused by the presence of aluminium.

It may be noted that the $R(T)$ data on $\mathrm{Bi}-\mathrm{Ag}$ indicate higher content of high- $T_{\mathrm{c}}$ phase, 2223 which does not agree with that of $\chi^{\prime}(T)$ and the DD method. Further two interesting peculiarities are observed in the Ag-doped sample. $T_{c}(R=0)$ changes with increase in the sample current density when it is $0.3 \mathrm{~A} / \mathrm{cm}^{2}$ or more. It is considerably less than the critical current in the ceramic samples indicating the weak links of intergranular boundaries in the $\mathrm{Bi}-\mathrm{Ag}$ sample. The second peculiarity is related to the growth of dome (cupola) on the $R(T)$ curve at $85 \mathrm{~K}$ with increase in current density. This shows the presence of phase shunt with $T_{c} \simeq 85 \mathrm{~K}$ and high temperature phase which is supplied with increased current density. This observation agrees with our earlier remark on the blocking of dispersion segments of low- $T_{c}$ phase with high- $T_{c}$ phase, 2223. In other words, there are intergrowth structures in the sample. It may be pointed out that the superconducting properties of $\mathrm{Bi}-\mathrm{Ag}$ sample are similar to lead-doped sample (Kravchenko et al 1990).

\section{Conclusion}

The study of superconducting properties of doped samples with their phase composition reveals the effect of alloying that leads to the formation of different polytypoids with high- $T_{c}$ phase 2223 , a varied degree of local lattice distortion of the superconducting phases and a sharp spatial distribution of impurity phases in the specimens. The degree of long-range ordering that distinguishes one polytypoid from the other also determines the superconducting properties. Such a correlation found by us using the DD method clearly focusses the importance of long-range ordering in the $\mathrm{Bi}$-based systems. Our work also points the need for other alloying elements that would stabilize the orderly arranged multilayer structure in Bi-based high- $T_{\mathrm{c}}$ phase. 


\section{Acknowledgement}

The work was carried out when one of the authors (BVR) was at the Institute of Inorganic Chemistry (IIC), Novosibirsk, USSR as a visiting scientist under Indo-USSR ILTP on Electronic Materials. The authors wish to thank Acad. F.A. Kuznetsov, Director of IIC for encouragement and suggestions.

\section{References}

Green S M, Mei Y, Manzi, Luo H L, Ramesh R and Thomas G 1989 J. Appl. Phys, 66728

Jin S, Sherwood R C, Tiefel T H, Kammlott, Fastnacht R A, Davis M E and Zahurak 1988 Appl. Phys. Lett. 521628

Kanai T, Kamo T and Matsudo S 1989 Jpn J. Appl. Phys. 28 L551

Kravchenko V S et al 1990 Izv. Sib. Br. Acad. Sci. Series (accepted)

Maeda H, Tanaka Y, Fuzitomi M and Asano T 1988 Jpn J. Appl. Phys. 27 L209

Malachov V V 1986 Dokl. Acad. Sci. USSR 2901152

Malachov V V 1989 J. Anal. Chem. 191177

Maxwell E 1965 Rev. Sci. Instrum. 36533

Reddi B V, Bezverkhy P P, Bogoljubov N A, Martynets V G and Matizen E V 1989a Preprint

Reddi B V, Romanenko A I, Mirunov Yu I, Kozeeva L P, Shaburova V P and Fedorov 1989b Preprint Shi D, Tang M, Vandervort K and Claus H 1989 Phys. Rev. B39 9091

Tallon J L, Buckley R G, Gilberd, Presland M R, Brown I W M, Bowden M E, Christian L A and Goguel R 1988 Nature (London) 333153

Vasilyeva I G, Reddi B V, Boldireva N N, Kuropjatnik I N, Romanenko A I and Malachov V V 1990 Superconductivity: Physics, Chemistry and Engineering (Moscow) (accepted) 